\title{
PINTURAS MEXICANAS DEL SIGLO XVIII EN PERU Y BOLIVIA
}

\author{
$\mathbf{P} \mathbf{O}$
}

\section{JOSE DE MESA Y TERESA GISBERT}

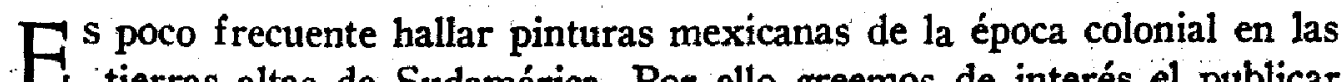
D tierras altas de Sudamérica. Por ello creemos de interés el publicar
un par de obras mexicanas, ambas del siglo xvir. Una se halla en el Cuzco y la otra en Sucre, Bolivia. Juzgamos que ambas son de valor, para estudiar la obra de los respectivos maestros que las signan.

El primer cuadro de que trataremos, de regulares dimensiones, es una copia de la Virgen de Guadalupe de México, con el retrato de un donante infantil, al pie. Se hallaba en 1947 en el Colegio Nacional de Mujeres, antiguo Hospital de San Juan de Dios, en el Cuzco. ${ }^{1}$ El estado del lienzo es aceptable.

La imagen representada, la de Guadalupe, es copia de la milagrosa. Pero en la copia, el pintor no ha podido sustraerse a las corrientes de la época en que la realiza, mediados del siglo xvin. El rostro de la virgen es muy estilizado y los paños, especialmente el manto, pese a que tratan de seguir al original, se estremecen por un viento barroco que los vuela. $\mathrm{El}$ dibuja de la primavera en la túnica es claramente dieciochesco. Es inusual, el añadido de un angelito que soporta la divina imagen en los aires. Los resplandores de Maria, se pierden en el fondo de tunas nubes "cumulus" esterotipadas. Donde el maestro mexicano da claras pruebas de su talento es en el retrato del donante, que por ahora es inidentificable.

1 La primera noticia sobre este cuadro la dio el Padre Rubén Vargas Ugarte en Ensayo de un diccionario de artífices de la América meridional, 1947. p. 288. 
El representado es un niño de unos siete $u$ ocho años. Se halia vestido a la usanza de la época, con amplia casaca de puños volteados, chaleco bordado y amplia chorrera. Al pie del cuadro hay una leyenda que dice: "VERDADERO RETRATO DE LA Sta. IMAgen DE Na, Sra. de GUAda LUPE DE MEXIco." La firma del autor aparece en el costado derecho del cuadro: "Joseph de Alcibar me pinxit Mexici 1754." 2

Buscando entre los maestros mexicanos de hacia medio siglo, efectivamente encontramos al maestro Alcíbar.

Don José de Alcibar, figura según el malogrado historiador del arte mexicano, Manuel Toussaint, entre los discípulos de Miguel Cabrera. " Se presume que nació entre 1725 y 1730 . Alcíbar comienza a trabajar en México, hacia 1751, año en que firma sus primeros cuadros. Luego forma parte de la Academia de Pintores, establecida en México en 1753. * Continúa pintando, gran cantidad de cuadros y láminas durante tres décadas. A la fundación e inauguración oficial de la Real Academia de San Carlos de Nueva España en 1785, don Jerónimo Antonio Gil, su director, llama a Alcibar para colaborar como profesor de pintura, junto con otros maestros coloniales, como Clapera, Sandoval, Gutiérrez, López, Sáenz, etc. Esta designación se hizo en forma provisional. Para la institución se necesitaban profesores académicos y los llamados, eran maestros aferrados todavia al estilo barroco. ${ }^{\circ}$ Alcíbar sigue trabajando en las décadas siguientes, pues cuadros firmados por él se conservan en 1801. Aparece como Teniente de Director en la Academia de San Carlos, hasta 1806. Debió fallecer hacia 1807 a edad muy avanzada, en la misma ciudad de México.

La producción de Alcibar, parcialmente catalogada por Agustín Velázquez Chávez, debido a su larga vida, es bastante grande. ${ }^{\top}$ La mayoría de sus obras, son cuadros de tema religioso, algunos son retratos.

Indudablemente entre estos últimos, se encuentra la mejor producción de este maestro. Coincidimos con Toussaint, en que el mejor retrato

2 Ibidem, p. 288. Hay facsímiles de cuatro firmas de Alcibar en Abelardo Cartillo y Gariel: Autógrafos de pintores colomiales. México, 1953.

3 Manuel Toussaint. Arte Colonial en Mético. México, 1948, p. 346.

4 Agustin Velázquez Chávez. Tres siglos de pintura colonial mexicana, p. 285. En esta obra, hay un extenso catálogo de las obras de Alcibar.

5 Manuel Toussaint. O.p. cif., pp. 406 y 407.

6 Ibidem, p. 407.

7 Ver Velázquez Chávez. Op. cit., p. 285 a 287. 
es el de Sor María Ignacia de la Sangre de Cristo, actualmente en el Museo Nacional de Historia. ${ }^{8}$ En cambio, la obra religiosa de Alcíbar tiene altibajos. Sus cuadros de este tema, reflejan a un maestro que lucha entre el barroco de su juventud y las nuevas tendencias clasicistas que se impusieron a partir de la séptima década del siglo xvirr. En sus cuadros de las Galerias de la Granja, ${ }^{\circ}$ se ve más orientado hacia el academismo. Por el contrario, el cuadro del Cuzco, fechado en 1754, es representativo del barroquismo aún imperante en México hacia mitad del siglo.

El cuadro de la Virgen de Guadalupe, que publicamos, es uno de los mejores, entre la producción religiosa, del maestro José de Alcíbar, que es uno de los más típicos representantes de la transición en la pintura mexicana del siglo xvirr.

- Del pintor Nicolás Enríquez dice el profesor Toussaint: "no es menor que cualquiera de los pintores secundarios que hemos estudiado en esta época (siglo xvin)". ${ }^{10}$ Según Velázquez Chávez, aparecen obras de este pintor, firmadas desde 1730 a $1771 .{ }^{11}$ No se conoce el lugar de su nacimiento; se afirma que vivió hasta 1787. ${ }^{12}$ Algunas de sus obras se hallan en la ciudad de Guadalajara. ${ }^{18}$ Sin embargo, en todas sus firmas, en las que coloca lugar, éste es siempre México. Ello hace presumir que desarrolló su arte en la capital de Nueva España. Las obras hasta ahora conocidas de Enríquez podrían dar la razón al señor Toussaint; no así la que se halla en la Colección Urioste de Sucre, Bolivia.

Se trata de una pequeña lámina de cobre $(0.28 \times 0.24)$, pintada al óleo con el busto del Salvador. Es una pequer̂́a obra maestra tanto por el dibujo, que es el más perfecto realizado por Enriquez, como por el suave colorido todo bañado por un tinte plateado. El modelado del rostro es perfecto y la representación de las calidades muy correcta. El tratamiento del cabello y las telas alcanzan alturas de virtuosismo.

8 Lo reproduce Toussaint. Op. cit., fig. 299.

9 Reproducidos en Velázquez Chávez. Op. cit., figuras 97 y 98 . Representan Nuestra Señora del Refugio y Nuestra Señora de la Merced.

10 Toussaint. Op. cit., p. 355.

11 Velázquez Chávez. Op. cit., p. 299.

12 Velázquez transcribe un texto de Toussaint. Ibidem, p. 299.

13 El catálogo de Enríquez esth en Velízquez Chivez. Op. cit., p. 299 y 300. Los cuadros de Guadalajara se hallan firmados en 1768 en México. Toussaint. Op. cit., p. 355. 
Si comparamos esta obra con las demás conocidas y publicadas de Enriquez, ${ }^{14}$ vemos que es una de las más tardías conocidas y que supera de lejos a otras de sus producciones similares, como el San Juan Nepomuceno del Museo de Filadelfia o el llamado San Camilo de Lelis, ${ }^{15}$ de la Colección Pérez Salazar.

La firma del cuadro de Sucre: "Nicolaus Enriqz. Mexici A. 1769", coincide con las ya publicadas. Prueba una vez más su trabajo en México y da una fecha nueva para su vida activa. Creemos que el Salvador de la Colección Urioste de Sucre es de importancia para la comprensión y estudio de la obra de Nicolás Enríquez, que quizás no sea un "pintor secundario", como hasta hoy se ha considerado.

Respecto a la procedencia de las dos obras reseñadas diremos que de la del Cuzco, no sabemos absolutamente nada. Debió pasar al Perú en la segunda mitad del siglo xvirr. Aquella en la Colección Urioste de Sucre, pasó a Bolivia a mediados del siglo xIX, traida por antecesores de su actual poseedor, que la adquirieron a bordo de un barco. ${ }^{16}$ :

14 Se reproducen obras de Enríquez en Velázquez Chávez. Op. cit., figuras 112 , 113 y 114. Son aparición de la Virgen y Jesús a varios Santos de 1738, San Camilo de Lelis (ver nota 15) y San Juan Nepomuceno.

15 Parece que se tratara de San Francisco de Paula.

- 16 Quien nos proporcionó las noticias del cuadro, y nos dio una fotografía de él fue nuestro bien amigo Jaime Uroiste, quien es su actual propietario en Sucre, Bolivia. 
DOI: http://dx.doi.org/10.22201/iie.18703062e.1959.28.666

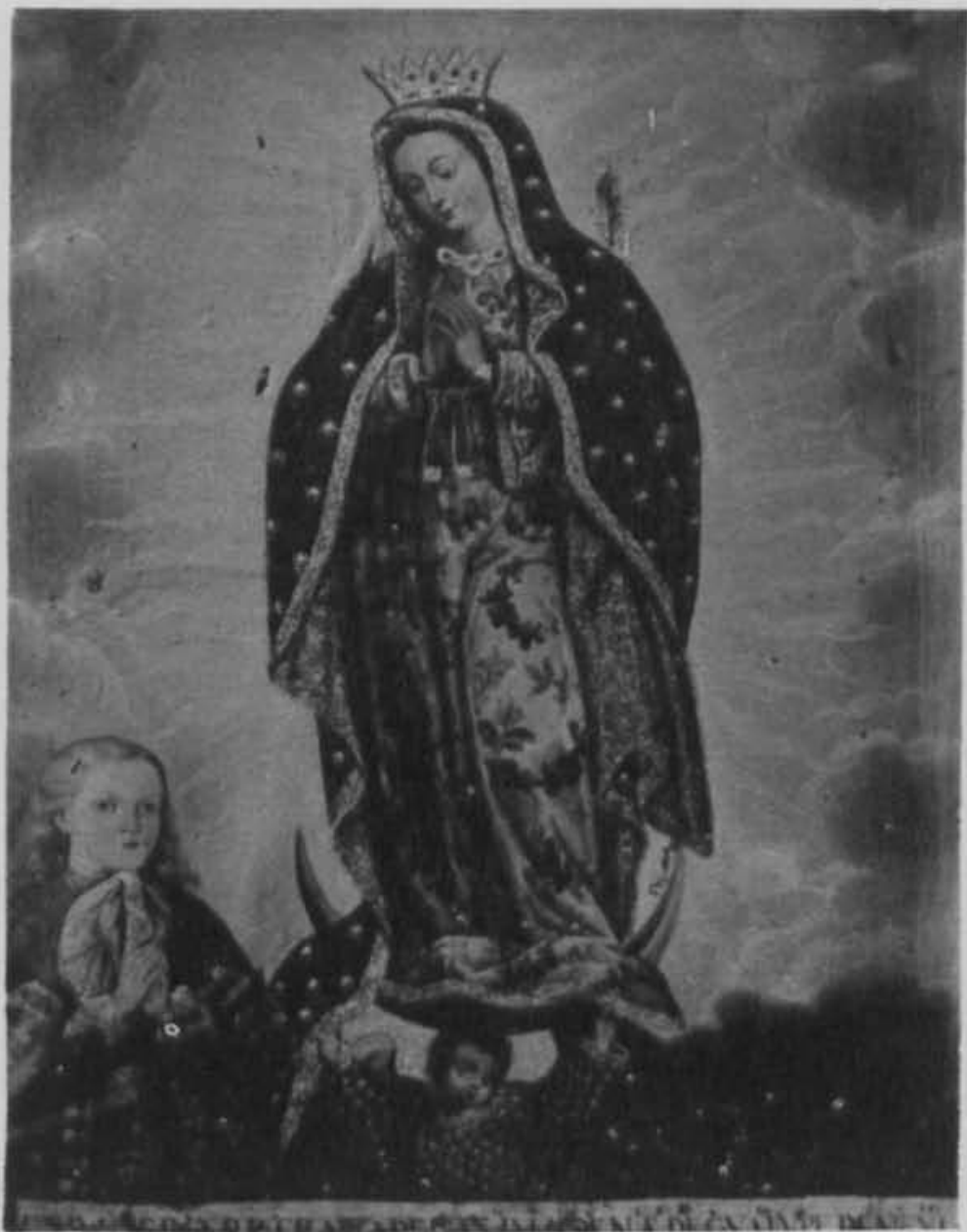

1. José de Alcibar. Nuestra Señora de Guadalupe. México, 1754. Foto Nishiama, Cuzco, Perú. 
DOI: http://dx.doi.org/10.22201/iie.18703062e.1959.28.666

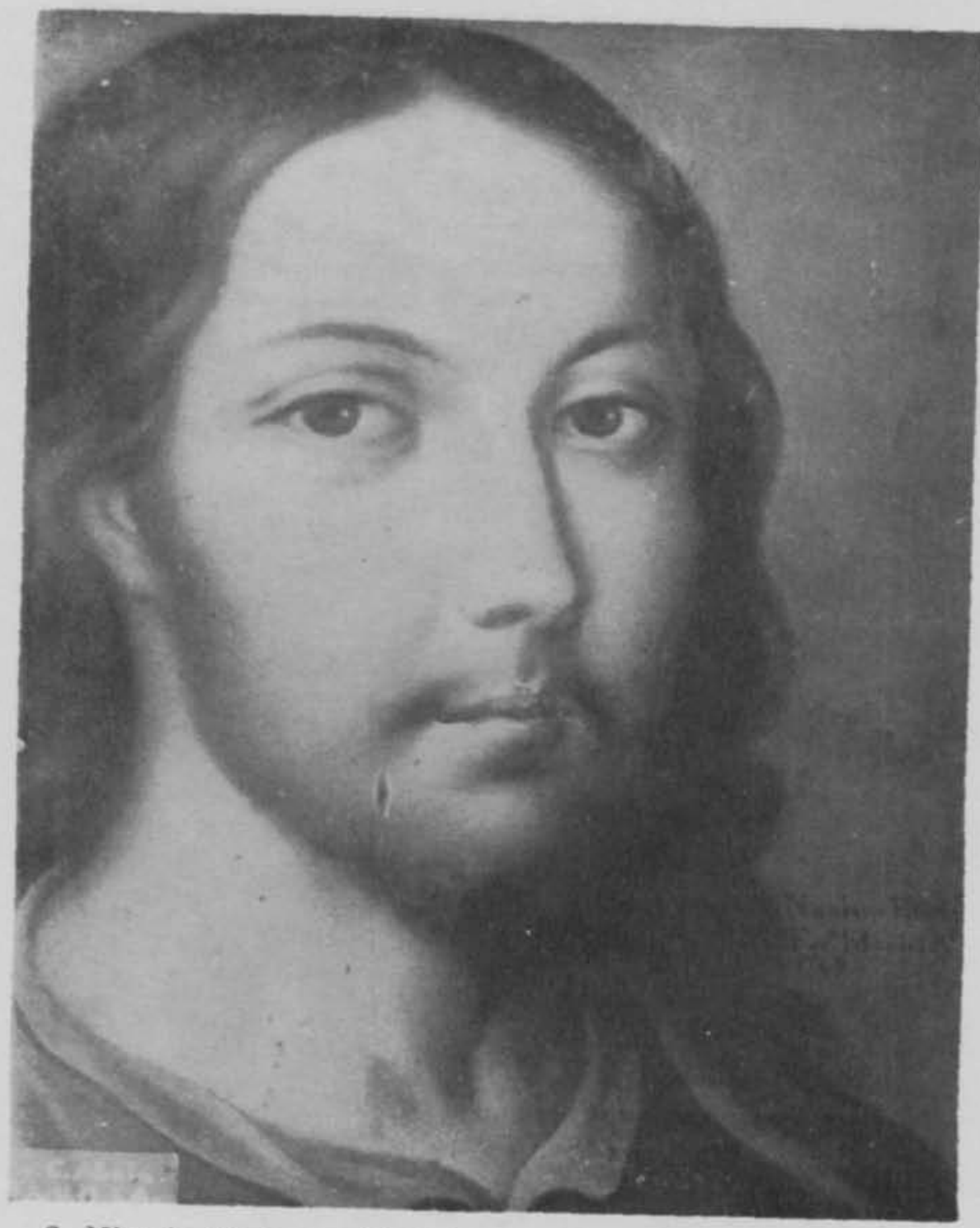

2. Nicolás Enriquez. El Salvador. México, 1769. Col. Urioste Sucre, Bolivia. Foto Abela. Univ. de La Paz. 